\title{
Content Analysis tentang Pembelajaran Kolaboratif Berbasis Open Ended untuk Meningkatkan Kepercayaan Diri Siswa Dalam Belajar Matematika
}

\author{
Nurhayati \\ Pendidikan Matematika, STKIP Singkawang, Indonesia \\ Jl. STKIP, Kel. Naram, Kec. Singkawang Utara, Singkawang, 79251 \\ Email:nurhayati@stkipsingkawang.ac.id,
}

Article History:

Received: 11-10-2019; Received in Revised: 10-07-2020; Accepted: 19-08-2020

\begin{abstract}
This article presents the results of content analysis of 19 books and 18 journals grouped according to the topic of collaborative learning, open-ended approach, and students' self confidence in learning mathematics. From this analysis, it is found that collaborative learning is highly recommended. The tasks given should use open-ended problems and intensively use various approaches. In the world of education, the students should be given the freedom to exchange ideas with other friends, while the teacher just acts as a facilitator, not as an expert. By learning that way, it is expected that the students can demonstrate clearly when they have to work individually and when they have to work collaboratively; this can indirectly increase the students' self confidence.
\end{abstract}

Keywords: Collaborative Learning; Open-Ended; Self Confidence.

\begin{abstract}
Abstrak
Artikel ini menyajikan hasil analisis content terhadap 19 buku dan 18 jurnal yang dikelompokkan sesuai dengan topik pembelajaran kolaboratif, pendekatan open-ended, dan kepercayaan diri siswa dalam belajar matematika. Dari analisis tersebut diperoleh bahwa pembelajaran kolaboratif sangat disarankan untuk digunakan. Tugas-tugas yang diberikan seharusnya menggunakan permasalahan open-ended dan secara intensif menggunakan berbagai macam pendekatan. Dalam dunia pendidikan sebaiknya siswa diberikan kebebasan untuk bertukar pikiran dengan teman lainnya sedangkan guru cukup berperan sebagai fasilitator bukan sebagai seorang ahli. Dengan pembelajaran yang seperti ini, harapannya mereka bisa mendemonstrasikan dengan jelas kapan mereka bekerja sendiri dan kapan mereka bekerja bersama-sama, hal ini secara tidak langsung dapat meningkatkan kepercayaan diri siswa.
\end{abstract}

Kata Kunci: Pembelajaran Kolaboratif; Open-Ended; Kepercayaan Diri. 


\section{Pendahuluan}

Di Indonesia, terdapat berbagai tujuan pembelajaran yang telah dirumuskan. Tujuan pembelajaran tersebut dituangkan dalam Permendikbud Nomor 22 Tahun 2016¹. Di dalam Permendikbud tersebut dibahas berbagai macam prinsip pembelajaran. Beberapa dari prinsip pembelajaran yang dirumuskan yaitu pembelajaran yang menekankan pada peserta didik untuk mencari tahu, pembelajaran yang menekankan pada jawaban divergen yang memiliki kebenaran multi dimensi dan pembelajaran berbasis kompetensi. Salah satu dari kompetensi yang seharusnya dimiliki oleh siswa berdasarkan Permendikbud Nomor 21 Tahun 2016 yaitu memiliki rasa ingin tahu, kepercayaan diri, dan ketertarikan pada matematika².

Pembelajaran diarahkan untuk mengembangkan semua potensi peserta didik menjadi kompetensi yang diharapkan, salah satunya adalah kepercayaan diri siswa. Menurut Srivastava, kepercayaan diri adalah percaya pada diri sendiri dan kemampuan diri, suatu sikap mental yang mempercayai atau mengandalkan diri sendiri, dan seberapa optimis seseorang untuk mencapai tujuan pada suatu situasi tertentu. Sehingga dengan adanya kepercayaan diri, diharapkan siswa dapat menyelesaikan semua tugas yang diberikan dengan mandiri dan maksimal. Oleh karena itu penting untuk merancang pembelajaran yang dapat meningkatkan kepercayaan diri siswa.

Namun pada kenyataannya, pembelajaran di Indonesia masih menerapkan teacher centered (Bjork) ${ }^{3}$. Sehingga aspek kepercayaan diri siswa masih luput dari perhatian. Apabila situasi ini tidak segera diatasi, maka kompetensi yang diinginkan tidak dapat tercapai. Oleh karena itu, perlu dicari berbagai macam solusi supaya kompetensi yang diinginkan dapat tercapai. Salah satu solusi yang ditawarkan adalah menggunakan pembelajaran kolaboratif dengan pendekatan open-ended.

1 Republik Indonesia, "Peraturan Menteri Pendidikan Dan Kebudayaan Nomor 22 Tahun 2016 Tentang Standar Proses Pendidikan Dasar Dan Menengah," Jakarta: Kementerian Pendidikan Dan Kebudayaan, 2016.

2 Menteri Pendidikan Nasional, "Peraturan Menteri Pendidikan Nasional Republik Indonesia Nomor 22 Tahun 2006 Tentang Standar Isi Untuk Satuan Pendidikan Dasar Dan Menengah" (Menteri Pendidikan Nasional Republik Indonesia, 2006), https://www.academia.edu/8728084/PERATURAN_MENTERI_PENDIDIKAN_NASIONAL_RE PUBLIK_INDONESIA_NOMOR_22_TAHUN_2006_TENTANG_STANDAR_ISI_UNTUK_SATUAN_P ENDIDIKAN_DASAR_DAN_MENENGAH.

3 Christopher Bjork, Indonesian Education: Teachers, Schools, and Central Bureaucracy (Routledge, 2005). 
Menurut Goodsell pembelajaran kolaboratif membuat siswa menjadi lebih terarah dalam mengungkapkan ide-ide di dalam kelas ${ }^{4}$. Mereka membangun kepercayaan diri dan keahlian mereka dalam mengungkapkan ide yang mereka miliki dalam pembelajaran saat menjawab pertanyaan, mendengarkan dengan seksama dan merespon pertanyaan dari teman lain. Mereka membangun kemampuan mereka untuk tetap fokus, mempertahankan suatu ide, membangun hubungan dengan beberapa siswa dan belajar cara menolak atau menerima pendapat siswa lain dengan sopan.

Murni mengungkapkan bahwa pendekatan open-ended adalah pendekatan dalam pembelajaran yang memberikan kesempatan kepada siswa untuk mendapatkan pengetahuan, pengalaman, mengetahui dan memecahkan suatu permasalahan dengan berbagai teknik ${ }^{5}$. Pembelajaran dengan pendekatan open-ended berjalan dengan baik apabila dilakukan dalam kelompok. Hal ini disebabkan karena karakteristik dari pendekatan ini adalah memerlukan pengonstruksian berbagai jenis ide, sehingga akan lebih efektif jika siswa belajar dalam kelompok.

Berdasarkan uraian yang telah dipaparkan, terdapat masalah yang terjadi di lapangan yaitu pembelajaran di sekolah masih menggunakan teacher centered dan pembelajaran di sekolah belum memperhatikan kepercayaan diri siswa. Padahal kepercayaan diri perlu dikembangkan ataupun mendapat perhatian khusus. Oleh karena itu, perlu adanya suatu kajian secara content analysis terhadap sumber-sumber ilmiah yang berisi tentang pembelajaran kolaboratif dengan pendekatan open-ended dan peningkatan kepercayaan diri siswa. Dari sini diharapkan sebagai guru memiliki referensi yang jelas tentang pembelajaran kolaboratif dengan pendekatan open-ended dan peningkatan kepercayaan diri siswa sehingga permasalahan yang terjadi di lapangan terkait dengan hal tersebut dapat segera diselesaikan. 1992.

4 Anne S. Goodsell, "Collaborative Learning: A Sourcebook for Higher Education,"

${ }^{5}$ M. Murni, "Open-Ended Approach in Learning to Improve Students Thinking Skills in Banda Aceh," International Journal of Independent Research and Studies (IJIRS) 2, no. 2 (2013): 95-101. 


\section{Metode}

Jenis penelitian yang digunakan adalah studi kepustakaan (Library Research). Studi kepustakaan adalah teknik pengumpulan data dengan melakukan penelaahan terhadap buku, literature, catatan serta berbagai laporan yang berkaitan dengan masalah yang ingin dipecahkan ${ }^{6}$. Sumber data yang digunakan terdiri dari 19 buku dan 18 jurnal tentang pembelajaran kolaboratif, pendekatan open-ended, dan kepercayaan diri. Teknik analisis data yang digunakan adalah metode analisis isi (content analysis). Tahapantahapan dalam analisis yang dilakukan adalah proses memilih, membandingkan dan menggabungkan berbagai istilah sehingga diperoleh berbagai pengertian atau teori-teori yang relevan.

\section{Hasil dan Diskusi}

Landasan teori mengenai model pembelajaran kolaboratif dengan pendekatan open-ended dapat meningkatkan kepercayaan diri tersusun dalam hasil kajian yang meliputi: 1) Latar belakang dan perkembangan teori pendekatan open-ended, 2) Latar belakang dan perkembangan teori model pembelajaran kolaboratif, 3) Konsep tentang pendekatan open-ended, 4) Konsep tentang model pembelajaran kolaborati, 5) Konsep tentang kepercayaan diri, 6) Konsep tentang model pembelajaran kolaboratif dengan pendekatan open-ended dapat meningkatkan kepercayaan diri.

Sumber pustaka yang digunakan untuk konsep tentang pendekatan open-ended yakni buku yang ditulis oleh Becker \& Shimada (2005) ${ }^{7}$, Cowan $(2006)^{8}$ dan Nohda (2000) ${ }^{9}$. Jurnal yang ditulis oleh Murni (2013) ${ }^{10}$, Noparit $(2005)^{11}$, Trochim \& Jackson $(2002)^{12}$ dan Yee $(2002)^{13}$. Pendekatan openended secara komprehensif berisi tentang definisi pendekatan open-ended,

${ }^{6}$ Abdi Mirzaqon T, "Studi Kepustakaan Mengenai Landasan Teori Dan Praktik Konseling Expressive Writing," Jurnal BK Unesa 8, no. 1 (2017).

${ }^{7}$ Jerry P. Becker and Shigeru Shimada, The Open-Ended Approach: A New Proposal for Teaching Mathematics. (ERIC, 1997).

8 Pamela Cowan, Teaching Mathematics: A Handbook for Primary and Secondary School Teachers (Routledge, 2006).

${ }_{9}$ Nobuhiko Nohda, "Teaching by Open-Approach Method in Japanese Mathematics Classroom.," 2000.

${ }^{10}$ Murni, "Open-Ended Approach in Learning to Improve Students Thinking Skills in Banda Aceh."

11 Tipparat Noparit, "Developing Instruction Based on Open Approach and Its Impact on Levels of Geometric Thinking and Geometric Achievement of Eighth Grade Students" (PhD Thesis, Dissertation, Ed. D.(Mathematics Education). Bangkok: Graduate School ..., 2005).

12 Kristin M. Jackson and William MK Trochim, "Concept Mapping as an Alternative Approach for the Analysis of Open-Ended Survey Responses," Organizational Research Methods 5, no. 4 (2002): 307-336.

13 Foong Pui Yee, "Using Short Open-Ended Mathematics Questions to Promote Thinking and Understanding," in Proceedings of the 4 Th International Conference on The Humanistic Renaissance in Mathematics Education, Palermo, Italy, 2002. 
strategi pendekatan open-ended, periode pembelajaran dalam pendekatan open-ended, klasifikasi masalah open-ended, kekurangan dan kelebihan pendekatan open-ended. Berdasarkan sumber rujukan tersebut pendekatan open-ended adalah pendekatan yang dicetuskan oleh Becker dan Shimada pada tahun 1997. Pendekatan open-ended merupakan pendekatan pembelajaran yang menekankan proses untuk mendapatkan banyak jawaban yang benar yang diberikan dari suatu permasalahan "yang belum lengkap" untuk mengembangkan pengalaman siswa dalam menemukan sesuatu dalam suatu proses.

Sumber pustaka yang digunakan untuk konsep tentang model pembelajaran kolaboratif yakni buku yang ditulis oleh Adams \& Hamm $(2010)^{14}$, Feurt (2008) ${ }^{15}$, Goodsell, Maher, Tinto, et Al (1992) ${ }^{16}$, Jalongo, Rieg \& Helterbran (2007) ${ }^{17}$, Jones (2014) ${ }^{18}$, Jones, Rasmussen, \& Moffitt (1997) ${ }^{19}$, Luzzato \& Dimarco $(2010)^{20}$, Roberts (2004) ${ }^{21}$, Roberts $(2005)^{22}$, dan Watkins, Carnell \& Lodge (2007) ${ }^{23}$. Jurnal yang ditulis oleh Edwards \& Jones (1999)24, Panitz (1999)25, Falkner \& Munro (2009)26 dan Laal \& Laal $(2011)^{27}$. Kajian mengenai konsep tentang model pembelajaran kolaboratif

14 Dennis Adams and Mary Hamm, Demystify Math, Science, and Technology: Creativity, Innovation, and Problem-Solving (R\&L Education, 2010).

15 Christine Baumann Feurt, "Collaborative Learning Guide for Ecosystem Management," 2008.

16 Goodsell, "Collaborative Learning."

17 Mary Renck Jalongo, Sue A. Rieg, and Valeri R. Helterbran, Planning for Learning: Collaborative Approaches to Lesson Design and Review (Teachers College Press, Columbia University, 2007).

18 Elizabeth A. Jones, "Examining the Influence of Structured Collaborative Learning Experiences for Graduate Students.," Journal on Excellence in College Teaching 25 (2014).

19 Beau Fly Jones, Claudette M. Rasmussen, and Mary C. Moffitt, Real-Life Problem Solving: A Collaborative Approach to Interdisciplinary Learning. (American Psychological Association, 1997).

${ }^{20}$ Edda Luzzatto and Giordano DiMarco, Collaborative Learning: Methodology, Types of Interactions and Techniques (Nova Science Publishers, Incorporated, 2009). 2004).

21 Tim S. Roberts, Online Collaborative Learning: Theory and Practice (IGI Global,

22 Tim S. Roberts, "Computer-Supported Collaborative Learning in Higher Education," in Computer-Supported Collaborative Learning in Higher Education (IGI Global, 2005), 1-18.

${ }^{23}$ Chris Watkins, Eileen Carnell, and Caroline Lodge, Effective Learning in Classrooms (Paul Chapman Educational Publishing, 2007).

24 Julie-Ann Edwards and Keith Jones, "Students' Views of Learning Mathematics in Collaborative Small Groups,” 1999.

25 Theodore Panitz, "Collaborative Versus Cooperative Learning: A Comparison of the Two Concepts Which Will Help Us Understand the Underlying Nature of Interactive Learning.", 1999.

26 Katrina Falkner and David S. Munro, "Easing the Transition: A Collaborative Learning Approach," in Proceedings of the Eleventh Australasian Conference on Computing Education-Volume 95, 2009, 65-74.

27 Marjan Laal and Mozhgan Laal, “Collaborative Learning: What Is It?," ProcediaSocial and Behavioral Sciences 31 (2012): 491-495. 
secara komprehensif berisi tentang definisi model pembelajaran kolaboratif, prinsip-prinsip dalam pembelajaran kolaboratif, karakteristik utama dari pembelajaran kolaboratif, langkah-langkah model pembelajaran kolaboratif, penilaian dalam model pembelajaran kolaboratif, manfaat model pembelajaran kolaboratif, contoh model pembelajaran kolaboratif, dan struktur pembelajaran kolaboratif. Berdasarkan sumber tersebut, secara konsep pembelajaran kolaboratif adalah suatu model pembelajaran yang melibatkan kelompok pelajar yang heterogen dan memiliki perspektif yang berbeda untuk bekerja bersama dan saling berkontribusi dalam menyelesaikan suatu permasalahan, tugas atau membuat suatu produk.

Sumber pustaka yang digunakan untuk konsep tentang kepercayaan diri yakni buku yang ditulis oleh Blalock (2014) ${ }^{28}$, Burton \& Platts (2006) ${ }^{29}$, McElmeel (2002) ${ }^{30}$, McGee (2010) $)^{31}$, Preston (2007) $)^{32}$, dan Stevenson (2006) ${ }^{33}$. Jurnal yang ditulis oleh Goel \& Aggarwal (2012) ${ }^{34}$, Kennet (2006) ${ }^{35}$, Parachin (2003) ${ }^{36}$, Parsons, Croft \& Harrison (2011) ${ }^{37}$, Srivastava (2013), Wagman (1997)38, dan White (2009) ${ }^{39}$. Kajian mengenai konsep tentang kepercayaan diri secara komprehensif berisi tentang pengertian kepercayaan diri, indikator kepercayaan diri, teknik untuk meningkatkan kepercayaan diri, dan tahapan untuk mengembangkan kepercayaan diri. Berdasarkan sumber tersebut, secara konsep kepercayaan diri adalah salah satu sikap positif yang dimiliki setiap individu yang mencakup tentang kompetensi diri, penilaian diri dan kepercayaan terhadap suatu hal.

\footnotetext{
${ }^{28}$ Becky Blalock, Dare: Straight Talk on Confidence, Courage, and Career for Women in Charge (John Wiley \& Sons, 2013).

${ }^{29}$ Kate Burton and Brinley Platts, Building Self-Confidence for Dummies (John Wiley \& Sons, 2011).

30 Sharron L. McElmeel, Character Education: A Book Guide for Teachers, Librarians, and Parents. (Libraries Unlimited, 2002).

31 Paul McGee, Self-Confidence: The Remarkable Truth of How a Small Change Can Boost Your Resilience and Increase Your Success (John Wiley \& Sons, 2020).

32 David Lawrence Preston, 365 Steps to Self-Confidence (How To Books, 2005).

33 Nancy Stevensen, Young Person's Character Education Handbook, by the Editors at Jist (Indianapolis: JIST Publishing, 2006).

34 Manisha Goel and Preeti Aggarwal, "A Comparative Study of Self Confidence of Single Child and Child with Sibling," International Journal of Research in Social Sciences 2, no. 3 (2012): 89-98.

35 M Kenneth, The Scale of Confidence (London: ProQuest, 2006).

36 Victor M. Parachin, "Developing Dynamic Self-Confidence," Supervision 64, no. 3 (2003): 13-13.

37 Sarah Parsons, Tony Croft, and Martin Harrison, “Engineering Students' SelfConfidence in Mathematics Mapped Onto Bandura's Self-Efficacy," Engineering Education 6, no. 1 (2011): 52-61.

${ }^{38}$ S. K. Srivastava, "To Study the Effect of Academic Achievement on the Level of Self Confidence.," Journal of Psychosocial Research 8, no. 1 (2013).

39 Krista A. White, "Self-Confidence: A Concept Analysis," in Nursing Forum, vol. 44 (Wiley Online Library, 2009), 103-114.
} 
Sumber pustaka yang digunakan untuk konsep tentang model pembelajaran kolaboratif dengan pendekatan open-ended dapat meningkatkan kepercayaan diri yakni jurnal yang ditulis oleh Al-Absi $(2012)^{40}$, Cerbin (2010) ${ }^{41}$ dan Wismath \& Orr (2015) ${ }^{42}$. Kajian tentang model pembelajaran kolaboratif dengan pendekatan open-ended dapat meningkatkan kepercayaan diri berisi tentang pelaksanaan penggunaan model pembelajaran kolaboratif dengan pendekatan open-ended. Berdasarkan sumber tersebut, pendekatan open-ended yang dikombinasikan dengan pembelajaran kolaboratif memberikan petunjuk perkembangan siswa salah satunya adalah mengembangkan harga diri siswa yang berkaitan dengan kepercayaan diri siswa. Selain itu, kerja kelompok kolaboratif dianggap sebagai suatu sarana untuk meningkatkan kepercayaan diri matematika siswa.

\section{Kesimpulan}

Artikel ini telah menganalisis 19 buku dan 18 jurnal tentang pembelajaran kolaboratif, pendekatan open-ended, dan kepercayaan diri siswa dalam belajar matematika. Pembelajaran kolaboratif sangat disarankan untuk digunakan. Tugas-tugas yang diberikan seharusnya menggunakan permasalahan open-ended dan secara intensif menggunakan berbagai macam pendekatan. Atmosfer yang akan dibentuk dalam dunia pendidikan adalah siswa dengan pemikirannya sendiri dan bebas untuk bertukar pikiran dengan teman lainnya dan guru berperan sebagai fasilitator bukan sebagai seorang ahli. Dengan pembelajaran yang seperti ini, harapannya mereka bisa mendemonstrasikan dengan jelas kapan mereka bekerja sendiri dan kapan mereka bekerja bersama-sama, hal ini secara tidak langsung dapat meningkatkan kepercayaan diri siswa.

40 Mohammad Al-Absi, "The Effect of Open Ended Tasks as an Assessment Tool-on Fourth Graders' Mathematics Achievement, and Assessing Students' Perspectives About It," Jordan Journal of Educational Sciences 9, no. 3 (2013): 345-351.

${ }^{41}$ B Cerbin, “Collaborative Learning Techniques Workshop" (Makalah, UW-La Crosse, April 2010).

42 Shelly L. Wismath and Doug Orr, "Collaborative Learning in Problem Solving: A Case Study in Metacognitive Learning.", Canadian Journal for the Scholarship of Teaching and Learning 6, no. 3 (2015): 10. 


\section{Daftar Pustaka}

Adams, Dennis, and Mary Hamm. Demystify Math, Science, and Technology: Creativity, Innovation, and Problem-Solving. R\&L Education, 2010.

Al-Absi, Mohammad. "The Effect of Open Ended Tasks as an Assessment Toolon Fourth Graders' Mathematics Achievement, and Assessing Students' Perspectives About It." Jordan Journal of Educational Sciences 9, no. 3 (2013): 345-351.

Becker, Jerry P., and Shigeru Shimada. The Open-Ended Approach: A New Proposal for Teaching Mathematics. ERIC, 1997.

Bjork, Christopher. Indonesian Education: Teachers, Schools, and Central Bureaucracy. Routledge, 2005.

Blalock, Becky. Dare: Straight Talk on Confidence, Courage, and Career for Women in Charge. John Wiley \& Sons, 2013.

Burton, Kate, and Brinley Platts. Building Self-Confidence for Dummies. John Wiley \& Sons, 2011.

Cerbin, B. “Collaborative Learning Techniques Workshop.” Makalah, UW-La Crosse, April 2010.

Cowan, Pamela. Teaching Mathematics: A Handbook for Primary and Secondary School Teachers. Routledge, 2006.

Edwards, Julie-Ann, and Keith Jones. "Students' Views of Learning Mathematics in Collaborative Small Groups," 1999.

Falkner, Katrina, and David S. Munro. "Easing the Transition: A Collaborative Learning Approach." In Proceedings of the Eleventh Australasian Conference on Computing Education-Volume 95, 65-74, 2009.

Feurt, Christine Baumann. "Collaborative Learning Guide for Ecosystem Management," 2008.

Goel, Manisha, and Preeti Aggarwal. "A Comparative Study of Self Confidence of Single Child and Child with Sibling." International Journal of Research in Social Sciences 2, no. 3 (2012): 89-98.

Goodsell, Anne S. "Collaborative Learning: A Sourcebook for Higher Education," 1992.

Jackson, Kristin M., and William MK Trochim. "Concept Mapping as an Alternative Approach for the Analysis of Open-Ended Survey Responses." Organizational Research Methods 5, no. 4 (2002): 307336.

Jalongo, Mary Renck, Sue A. Rieg, and Valeri R. Helterbran. Planning for Learning: Collaborative Approaches to Lesson Design and Review. Teachers College Press, Columbia University, 2007.

Jones, Beau Fly, Claudette M. Rasmussen, and Mary C. Moffitt. Real-Life Problem Solving: A Collaborative Approach to Interdisciplinary Learning. American Psychological Association, 1997.

Jones, Elizabeth A. "Examining the Influence of Structured Collaborative Learning Experiences for Graduate Students." Journal on Excellence in College Teaching 25 (2014).

Kenneth, M. The Scale of Confidence. London: ProQuest, 2006.

Laal, Marjan, and Mozhgan Laal. "Collaborative Learning: What Is It?" Procedia-Social and Behavioral Sciences 31 (2012): 491-495. 
Luzzatto, Edda, and Giordano DiMarco. Collaborative Learning: Methodology, Types of Interactions and Techniques. Nova Science Publishers, Incorporated, 2009.

McElmeel, Sharron L. Character Education: A Book Guide for Teachers, Librarians, and Parents. Libraries Unlimited, 2002.

McGee, Paul. Self-Confidence: The Remarkable Truth of How a Small Change Can Boost Your Resilience and Increase Your Success. John Wiley \& Sons, 2020.

Menteri Pendidikan Nasional. "Peraturan Menteri Pendidikan Nasional Republik Indonesia Nomor 22 Tahun 2006 Tentang Standar Isi Untuk Satuan Pendidikan Dasar Dan Menengah." Menteri Pendidikan Nasional Republik Indonesia, 2006. https://www.academia.edu/8728084/PERATURAN_MENTERI_PENDID IKAN_NASIONAL_REPUBLIK_INDONESIA_NOMOR_22_TAHUN_2006_TE NTANG_STANDAR_ISI_UNTUK_SATUAN_PENDIDIKAN_DASAR_DAN_ME NENGAH.

Mirzaqon T, Abdi. "Studi Kepustakaan Mengenai Landasan Teori Dan Praktik Konseling Expressive Writing." Jurnal BK Unesa 8, no. 1 (2017).

Murni, M. "Open-Ended Approach in Learning to Improve Students Thinking Skills in Banda Aceh." International Journal of Independent Research and Studies (IJIRS) 2, no. 2 (2013): 95-101.

Nohda, Nobuhiko. "Teaching by Open-Approach Method in Japanese Mathematics Classroom.," 2000.

Noparit, Tipparat. "Developing Instruction Based on Open Approach and Its Impact on Levels of Geometric Thinking and Geometric Achievement of Eighth Grade Students." PhD Thesis, Dissertation, Ed. D.(Mathematics Education). Bangkok: Graduate School ..., 2005.

Panitz, Theodore. "Collaborative Versus Cooperative Learning: A Comparison of the Two Concepts Which Will Help Us Understand the Underlying Nature of Interactive Learning.," 1999.

Parachin, Victor M. "Developing Dynamic Self-Confidence." Supervision 64, no. 3 (2003): 13-13.

Parsons, Sarah, Tony Croft, and Martin Harrison. "Engineering Students' SelfConfidence in Mathematics Mapped Onto Bandura's Self-Efficacy." Engineering Education 6, no. 1 (2011): 52-61.

Preston, David Lawrence. 365 Steps to Self-Confidence. How To Books, 2005.

Republik Indonesia. "Peraturan Menteri Pendidikan Dan Kebudayaan Nomor 22 Tahun 2016 Tentang Standar Proses Pendidikan Dasar Dan Menengah." Jakarta: Kementerian Pendidikan Dan Kebudayaan, 2016.

Roberts, Tim S. "Computer-Supported Collaborative Learning in Higher Education." In Computer-Supported Collaborative Learning in Higher Education, 1-18. IGI Global, 2005.

- - - Online Collaborative Learning: Theory and Practice. IGI Global, 2004.

Srivastava, S. K. "To Study the Effect of Academic Achievement on the Level of Self Confidence." Journal of Psychosocial Research 8, no. 1 (2013).

Stevensen, Nancy. Young Person's Character Education Handbook, by the Editors at Jist. Indianapolis: JIST Publishing, 2006. 
Watkins, Chris, Eileen Carnell, and Caroline Lodge. Effective Learning in Classrooms. Paul Chapman Educational Publishing, 2007.

White, Krista A. "Self-Confidence: A Concept Analysis." In Nursing Forum, 44:103-114. Wiley Online Library, 2009.

Wismath, Shelly L., and Doug Orr. "Collaborative Learning in Problem Solving: A Case Study in Metacognitive Learning." Canadian Journal for the Scholarship of Teaching and Learning 6, no. 3 (2015): 10.

Yee, Foong Pui. "Using Short Open-Ended Mathematics Questions to Promote Thinking and Understanding." In Proceedings of the 4 Th International Conference on The Humanistic Renaissance in Mathematics Education, Palermo, Italy, 2002. 